\section{Commentary: Fool me once, shame on you, fool me twice, shame on me - preparing for acute aortic emergencies and the next wave of the COVID-19 pandemic}

\author{
Christopher Lau, MD, and Mario Gaudino, MD
}

The coronavirus disease 2019 (COVID-19) pandemic has completely altered the healthcare landscape within a very short period owing to the rapid influx of patients requiring medical attention related to the severe acute respiratory syndrome coronavirus 2 infection displacing patients needing other types of medical attention. Entire hospital systems were restructured to accommodate the intensive needs of patients with COVID-19, and hospital capacity was quickly overwhelmed in terms of actual space and the necessary personnel. Although routine care and elective procedures could be safely postponed, the resource-intensive pandemic limited the ability of hospitals to easily manage critical medical conditions such as acute aortic emergencies. The limitations put both patients and healthcare workers at risk by the potential for nosocomial transmission of the virus. In this issue of JTCVS, Mehta et $\mathrm{al}^{1}$ have presented a consensus algorithm for triaging and treating patients presenting with acute aortic emergencies during the COVID-19 pandemic. The algorithm aims to minimize the risk of exposure and transmission when treating patients in this emergent setting. The lessons learned in this pandemic should prepare us for a potential second wave or any future pandemics.

From the Department of Cardiothoracic Surgery, Weill Cornell Medicine, New York, NY.

Disclosures: The authors reported no conflicts of interest.

The Journal policy requires editors and reviewers to disclose conflicts of interest and to decline handling or reviewing manuscripts for which they may have a conflict of interest. The editors and reviewers of this article have no conflicts of interest.

Received for publication June 5, 2020; revisions received June 5, 2020; accepted for publication June 5, 2020; available ahead of print June 24, 2020.

Address for reprints: Mario Gaudino, MD, Department of Cardiothoracic Surgery, Weill Cornell Medicine, 525 East 68th St, New York, NY 10065 (E-mail: mfg9004@med.cornell.edu).

J Thorac Cardiovasc Surg 2021;161:54-5

$0022-5223 / \$ 36.00$

Copyright (c) 2020 by The American Association for Thoracic Surgery

https://doi.org/10.1016/j.jtcvs.2020.06.055

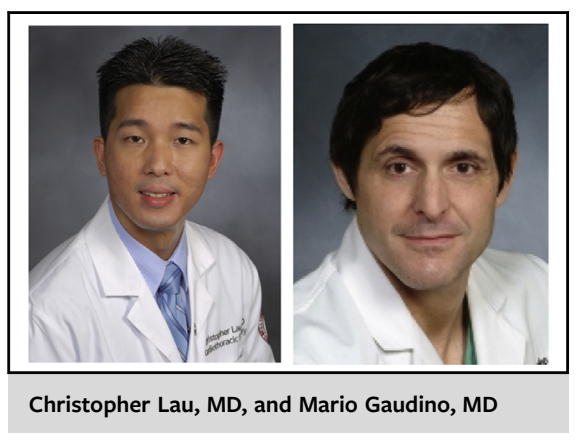

CENTRAL MESSAGE

Pandemics overload the health-

care system and hinder care of

emergent medical conditions.

Management algorithms pro-

mote safe and expedient care of

patients with acute aortic emer-

gencies during these times.

The COVID-19 pandemic has also led to a general avoidance of medical facilities by patients because of the fear of nosocomial transmission. This has led to a decreased number of patients presenting with emergencies such as ST elevation myocardial infarction and acute type A aortic dissection. ${ }^{2}$ However, it is unclear whether the incidence has truly decreased and those who do present might be in advanced stages of disease. It is wellknown that rapid surgical correction of acute aortic emergencies will usually lead to the best outcomes and that delays in treatment can be fatal. However, the safety of the healthcare workers and other hospital patients must be protected even in these emergent situations. The algorithm offered by Mehta et al ${ }^{1}$ provides a thoughtful and effective rapid triaging system according to the COVID19 diagnosis status of the patient. In brief, the treatment of patients whose COVID-19 status is unknown or positive requires the use of full COVID-19 personal protective equipment (PPE), COVID-19-designated operating rooms, and COVID-19 intensive care and/or postoperative care units. In contrast, patients with known COVID19-negative status can be cared for using routine universal precautions and care settings. Additionally, although not specifically addressed in their algorithm, consideration should be given to using N95 masks and face shields even when treating patients with negative COVID-19 status during potentially aerosolizing procedures, such as intubation or bronchoscopy, because of the small, but 
important, false-negative rates with the currently available COVID-19 testing methods.

With appropriate use of PPE and designated COVID-19 spaces, the risk of nosocomial transmission can be kept to a minimum. Undoubtedly, some healthcare workers have been inflicted with and succumbed to COVID-19 from work-related exposure. However, the transmission rates have been very low with adequate awareness and PPE use. In a series from a large hospital in Wuhan, China, the infection rate was $0.5 \%$ among first-line healthcare workers, and the rates were higher in the early stages of the outbreak when PPE use was less stringent. ${ }^{3}$ Proper algorithms can allow us to stay safe while providing expedient care to those with acute aortic emergencies.

\section{References}

1. Mehta CK, Malaisrie SC, Budd AN, Okita Y, Matsuda H, Fleischman F, et al. Triage and management of aortic emergencies during the coronavirus disease 2019 (COVID-19) pandemic: a consensus document supported by the American Association for Thoracic Surgery (AATS) and Asian Society for Cardiovascular and Thoracic Surgery (ASCVTS). J Thorac Cardiovasc Surg. 2021;161:48-53.

2. El-Hamamsy I, Brinster DR, DeRose JJ, Girardi LN, Hisamoto K, Imam MN, et al The COVID-19 pandemic and acute aortic dissections in New York: a matter of public health. J Am Coll Cardiol. May 15, 2020 [Epub ahead of print].

3. Lai X, Wang M, Qin C, Tan L, Ran L, Chen D, et al. Coronavirus disease 2019 (COVID-2019) infection among health care workers and implications for prevention measures in a tertiary hospital in Wuhan, China. JAMA Netw Open. 2020;3:e209666.
See Article page 48.

\section{Commentary: Managing thoracic aortic emergencies during a pandemic}

Roland Assi, MD, MMS, Arnar Geirsson, MD, and Prashanth Vallabhajosyula, MD

The coronavirus 2019 (COVID-19) pandemic continues to burden the health care infrastructure with unprecedented challenges. Management of acute aortic emergencies during a pandemic increases the complexity of an already resource-heavy disease.

Mehta and colleagues ${ }^{1}$ propose an algorithmic approach to the triage and management of thoracic aortic emergencies during the COVID-19 pandemic. We find the algorithm

\footnotetext{
From the Division of Cardiac Surgery, Department of Surgery, Yale University School of Medicine, New Haven, Conn.

Disclosures: Dr Geirsson is a member of Medtronic's Strategic Surgical Advisory Board. All other authors reported no conflicts of interest.

The Journal policy requires editors and reviewers to disclose conflicts of interest and to decline handling or reviewing manuscripts for which they may have a conflict of interest. The editors and reviewers of this article have no conflicts of interest.

Received for publication July 2, 2020; revisions received July 2, 2020; accepted for publication July 2, 2020; available ahead of print July 14, 2020.

Address for reprints: Prashanth Vallabhajosyula, MD, Division of Cardiac Surgery,

Department of Surgery, Yale University School of Medicine, 330 Cedar St, New

Haven, CT 06519 (E-mail: prashanth.vallabhajosyula@yale.edu).

J Thorac Cardiovasc Surg 2021;161:55-6

$0022-5223 / \$ 36.00$

Copyright (c) 2020 by The American Association for Thoracic Surgery

https://doi.org/10.1016/j.jtcvs.2020.07.026
}

-

